\title{
Posterior Reversible Encephalopathy Syndrome Following Meningitis in Pregnancy
}

\section{Hye-Na Park, Yun-Sook Kim}

Department of Obstetrics and Gynecology, Soonchunhyang University Cheonan Hospital, Soonchunhyang University College of Medicine, Cheonan, Korea

\begin{abstract}
Posterior reversible encephalopathy syndrome (PRES) is a clinical-neuroradiological entity characterized by headache, vomiting, mental change, and seizures as well as images suggesting leptomeningeal edema involving in most cases posterior regions of the brain, as proven by magnetic resonance imaging. PRES occurred in association with severe infection, autoimmune disease, postchemotherapy, and preeclampsia-eclampsia. Meningitis is an inflammation of the meninges. The most common causes of meningitis are viral and bacterial infections. While PRES is usually reversible, the early recognition and treatment of this syndrome is important to prevent permanent neurological disorders. The treatment is elimination of causal factors. We report a rare case of PRES after meningitis during pregnancy being treated with medical and rehabilitation treatment.
\end{abstract}

Keywords: Posterior reversible encephalopathy syndrome; Meningitis; Pregnancy

\section{INTRODUCTION}

Posterior reversible encephalopathy syndrome (PRES) is a clinical-neuroradiological entity, initially described in 1996 by Hinchey and his colleagues, as reversible posterior leukoencephalopathy [1]. This syndrome is characterized by headache, visual disturbances, seizures, altered mental change, and radiological findings of edema in the white matter of the brain areas perfused by the posterior brain circulation [2]. While most cases are due to systemic hypertension (HTN), other conditions and entities have been identified as etiologic or risk factors, such as immunosuppressant drugs use, nephrotic syndrome, sepsis, systemic lupus erythematosus, and meningitis [3-6].

\section{CASE REPORT}

A 33-year-old woman visited our Soonchunhyang University Cheonan Hospital for headache and fever. She was primigravida of 31 weeks' gestation with no past history and operation history. Her headache and fever had started a week ago before visiting our hospital. She had treated at local clinic by fluid and antipyretic-analgesics, but symptoms did not improve. So she was transferred to our clinic. When she visited our clinic, her body temperature was $38.6^{\circ} \mathrm{C}$ and had a severe headache and neck stiffness. With the impression of viral meningitis, conservative treatment with antipyretics and hydration was started. Also she had neck stiffness. By consultation of department of neurology, neurologists suspect viral meningitis. So, spinal tapping was done. Spinal tapping results were consistent with herpes viral meningitis, which the cerebrospinal fluid (CSF) findings were normal pressure, clear in color, glucose was $27 \mathrm{mg} / \mathrm{dL}$ (range, 40 to $70 \mathrm{mg} / \mathrm{dL}$ ), protein was 106.8 $\mathrm{mg} / \mathrm{dL}$ (range, 15 to $45 \mathrm{mg} / \mathrm{dL}$ ), red blood cell (RBC) count was 6 , white blood cell (WBC) count was 171 (polymorphonuclear leukocytes [PMNs] 15\%, lymphocytes 85\%), and adenosine deaminase was $8.6 \mathrm{U} / \mathrm{L}$. Serum glucose was $74 \mathrm{mg} / \mathrm{dL}$ (range, 70 to 110 $\mathrm{mg} / \mathrm{dL}$ ). Acid-fast and gram stains revealed negative. Enterovirus reverse transcription polymerase chain reaction, herpes simplex virus (HSV) type I and type II PCR, varicella zoster PCR, and mycobacterium tuberculosis (TB) PCR on the CSF sample were all negative results. 
On the day of admission, the findings of brain computed tomography (CT) without contrast enhancement were normal. On the day she admitted, anti-HSV immunoglobulin (Ig) G and Ig M were positive, and we started to use acyclovir in suspicion of herpes meningitis. All other laboratory tests were normal. CSF cultures including HSV were all negative findings. On India ink preparation in CSF, cryptococcus was not found.

On the third day after admission, the fever was absent for 24 hours and began to heat again from that night. We continued conservative treatments such as fluids, antivirals, and antipyretics. She had a headache, but her consciousness was clear. Until then, she was well aware of her fetal movements and had no uterine contractions. Suddenly she did not void by herself, so we inserted a Foley catheter into her. We injected her betamethasone $12 \mathrm{mg} \mathrm{ev}-$ ery 12 hours to prepare for emergency delivery.

On the 8th day of admission, the neurology department performed the follow-up spinal tapping. The results showed that WBC and RBC were decreased, but protein and glucose remained unchanged. Spinal tapping results were consistent with herpes viral meningitis and TB. The follow-up CT findings were normal. Just then, she suddenly made a strange noise, grabbed the catheter and intravenous line, and pulled it away. After a while she came back to the right mind, but she did not remember what she had done. Her mental status was getting worse and worse. We decided to do a cesarean section before her condition got worsened. On the 32nd weeks of pregnancy, she gave birth to 2,080 $\mathrm{g}$ of girl. The score of Apgar was 6 points in 1 minute and 8 points in 5 minutes. After the section, her consciousness came back for 5 hours, but soon became a stuporous mental status. She had a generalized tonic clonic seizure. We administered lorazepam intravenously to her. She had no self-breathing and moved to the neurosurgical intensive care unit (NICU) after tracheal intubation. We passed her into neurology. The brain magnetic resonance imaging (MRI) taken on the same day showed a favorable finding for leptomeningitis (Fig. 1). The results of TB test were all negative, but TB was strongly suspected in the repeated CSF test that day. So, neurologist finally decided to treat her with anti-TB and acyclovir. He administered to her acyclovir $710 \mathrm{mg} 3$ times, thiamine $100 \mathrm{mg}$, tazobactam $0.5 \mathrm{~g} 3$ times, dexamethasone $2 \mathrm{mg} 4$ times, fraxiparin 2,839 IU, human Ig G $27.5 \mathrm{mg}$, isoniazid $300 \mathrm{mg}$, rifampin 600 $\mathrm{mg}$, myambutol 1,200 mg, and pyrazinamide 2,000 mg while in the NCU. After 16 days of NCU care, she went to general ward. Transcutaneous electrical nerve stimulation was normal. However

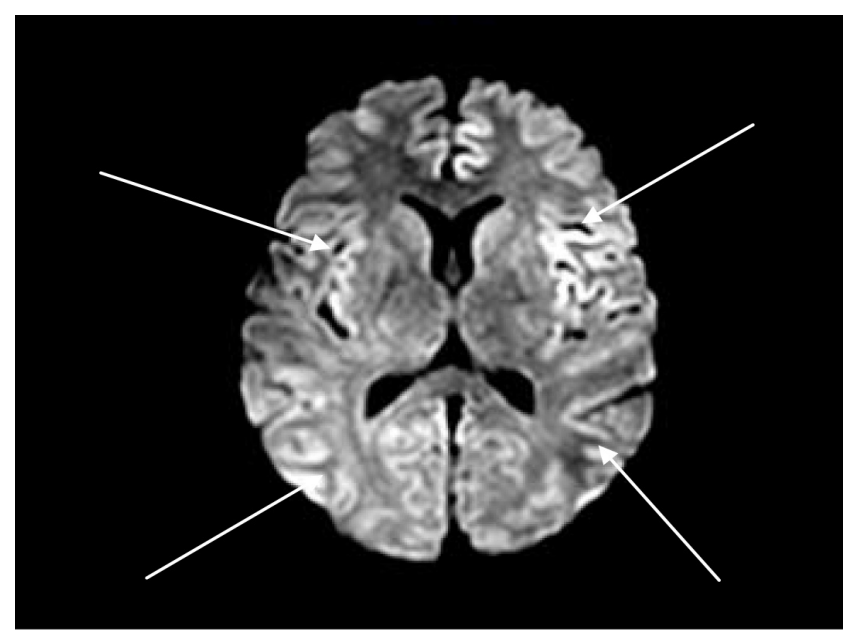

Fig. 1. Axial T2 weighted MRI image showing bilateral high-density areas in the white matter of both cerebral hemispheres (arrows). This image is revealing bilateral subcortical white matter temporo-occipital edema with leptomeningeal enhancement.

she appeared to have some sequelae of meningitis, such as lower limb muscle weakness and tingling sensation. She received a complex therapeutic exercise in the rehabilitation department every day. One month after being transferred to the general ward, her mental status was alert, so she was discharged with her baby while lying down. She continued rehabilitation after discharge. Her anti smooth muscle antibody was negative, 50\% hemolytic complement was $45 \mathrm{U} / \mathrm{mL}$ (range, 23 to $46 \mathrm{U} / \mathrm{mL}$ ), anti cardiolipin antibody Ig M and Ig $\mathrm{G}$ were negative, lupus anticoagulant screening was negative, anti-acetylcholine binding antibody was less than $0.02 \mathrm{nmol} / \mathrm{L}$ (range, 0 to $0.2 \mathrm{nmol} / \mathrm{L}$ ), and Japanese encephalitis antibody Ig $\mathrm{M}$ was negative.

Two months after discharge, knee jerk returned weakly and selfvoiding and standing became possible in three months after discharge. We stopped the TB drugs. She walked alone to visit our hospital in 110 days after her discharge.

\section{DISCUSSION}

PRES is often associated with pregnancy-induced HTN, and clinical presentation is similar when preeclampsia is associated. However, she did not have any proteinuria or HTN to meet the diagnostic criteria of preeclampsia patients. Meningitis caused by a bacterial infection is rare. Bacterial infections are serious and could cause life-threatening side effects if not treated with antibiotics. Viral meningitis is more common and far less serious com- 
Park HN, et al. • Posterior Reversible Encephalopathy Syndrome Following Meningitis

pared to bacterial meningitis. The infection is often difficult to diagnose because symptoms are similar to the common cold. Meningitis is not always easy to recognize. In a lot of cases, the illness progresses without any symptoms at all. During the initial phase, symptoms are often similar to flu symptoms. Individuals suffering from meningitis, however, could become seriously ill within a span of a few hours, so it is essential to recognize other symptoms of the condition [7]. These include headache, fever, muscle pain, nausea, vomiting, and cold hands and feet. If the symptoms persist, a spinal tapping is the only means of diagnosis. In viral meningitis, the result of spinal tapping was clear appearance, normal or slightly elevated opening pressure, high in protein, high in WBCs, high in early PMN, and high in late lymphocyte [8]. In this patient, her spinal tapping result was consistent with viral meningitis. However, all cultures were negative. After she became stuporous mental status, despite of the results of TB test were all negative, but TB was strongly suspected in the repeated CSF test. We finally decided to treat her with anti-TB and acyclovir.

Most people make a full recovery from meningitis, but it can sometimes cause serious, long-term problems and can be life threatening. Some of the most serious complications associated with meningitis are partial or total hearing loss, coordination, movement and balance problems, visual loss, and PRES. Additional treatment and long-term rehabilitation support may be required like in this patient [9].

In PRES, abnormal auto-regulatory response results in a destruction of the normal blood brain barrier and cumulates vascular edema [10]. Vascular edema is caused by HTN and endothelial injury [11]. Since the patient had no HTN, endothelial dysfunction was probably the cause of PRES. Edema can obstruct the circulation of the affected sites producing hypoxia with consequently adenosine triphosphate depletion resulting in sodium-potassium pump failure producing intracellular water retention $[12,13]$. It is produced secondary to endothelial damage resulting to coagulation pathway activation with a permeability increase, leading to vascular edema [14].

Bacterial and viral infections like meningitis also seem to have a role in the pathogenesis of PRES by endothelial injury and microcirculation disturbances. The microcirculation alterations are secondary to leukocyte micro vessels blockage reducing tissue perfusion [15].

The most common clinical symptom of PRES is headache. Other common signs are changes of consciousness such as lethargy, stupor, and irritability although coma may develop. Seizures may present as the initial clinical feature in some cases. There may be memory disturbances and concentration difficulty [16]. Although rare, there may be motor dysfunctions such as hemiparesis, dysuria, paraplegia, and ataxia [2]. The patient also had a headache and memory disorder at first, followed by changes in consciousness and seizures, resulting in paraplegia and ataxia. CT scan findings are negative in almost case of PRES. The complications of meningitis in pregnant women are rarely accompanied by changes in consciousness, and MRI is necessary to distinguish them from PRES and the treatment is similar. Therefore, the most appropriate image study is MRI [17]. The most common image findings are edema sign in the white matter of posterior portions of the brain, especially occipital and parietal areas, being in mainly bilateral [3]. This patient showed a favorable finding for PRES. It is very important to treat patients with PRES as soon as suspected to avoid the risk of irreversible complications. Treatment is to remove the causative agents as soon as possible. ICU admission must be done for continuous neurological, pulmonary, and cardiac status close monitoring [18]. General methods have to be taken in the complicated PRES such as in cases with seizures in which airway maintenance, including mechanical ventilation, may be needed, with antiepileptics such as lorazepam have to be injected. This patient also suffered seizures and we administered lorazepam, and she was moved to the NICU after intubation without consciousness and self-breathing.

Many cases of PRES have been reported since it was first reported and various causes have been identified. However, the precise mechanisms of pathogenesis have yet to be known. For each patient, rapid diagnosis and treatment are the most important. PRES is rarely reported after meningitis during pregnancy, so this case is rare and worthy of case report. We report a rare case of PRES in meningitis in pregnant woman with MRI diagnosis and treatment with review of the literatures.

\section{REFERENCES}

1. Lim MH, Kim DW, Cho HS, Lee HJ, Kim HJ, Park KJ, et al. Isolated cerebellar reversible leukoencephalopathy syndrome in a patient with end stage renal disease. Intern Med 2008;47:43-5.

2. Hinchey J, Chaves C, Appignani B, Breen J, Pao L, Wang A, et al. A reversible posterior leukoencephalopathy syndrome. N Engl J Med 1996;334:494-500.

3. Kozak OS, Wijdicks EF, Manno EM, Miley JT, Rabinstein AA. Status epilepticus as initial manifestation of posterior reversible encephalopathy 
syndrome. Neurology 2007;69:894-7.

4. Ishikura K, Ikeda M, Hamasaki Y, Hataya H, Nishimura G, Hiramoto R, et al. Nephrotic state as a risk factor for developing posterior reversible encephalopathy syndrome in paediatric patients with nephrotic syndrome. Nephrol Dial Transplant 2008;23:2531-6.

5. Bartynski WS, Boardman JF, Zeigler ZR, Shadduck RK, Lister J. Posterior reversible encephalopathy syndrome in infection, sepsis, and shock. AJNR Am J Neuroradiol 2006;27:2179-90.

6. El Karoui K, Le Quintrec M, Dekeyser E, Servais A, Hummel A, Fadel F, et al. Posterior reversible encephalopathy syndrome in systemic lupus erythematosus. Nephrol Dial Transplant 2008;23:757-63.

7. Cinque P, Cleator GM, Weber T, Monteyne P, Sindic CJ, van Loon AM. The role of laboratory investigation in the diagnosis and management of patients with suspected herpes simplex encephalitis: a consensus report. The EU Concerted Action on Virus Meningitis and Encephalitis. J Neurol Neurosurg Psychiatry 1996;61:339-45.

8. McGrath N, Anderson NE, Croxson MC, Powell KF. Herpes simplex encephalitis treated with acyclovir: diagnosis and long term outcome. J Neurol Neurosurg Psychiatry 1997;63:321-6.

9. Dupuis O, Audibert F, Fernandez H, Frydman R. Herpes simplex virus encephalitis in pregnancy. Obstet Gynecol 1999;94(5 Pt 2):810-2.

10. Alehan F, Erol I, Agildere AM, Ozcay F, Baskin E, Cengiz N, et al. Posterior leukoencephalopathy syndrome in children and adolescents. J Child Neurol 2007;22:406-13.

11. Yano Y, Kario K, Fukunaga T, Ohshita T, Himeji D, Yano M, et al. A case of reversible posterior leukoencephalopathy syndrome caused by transient hypercoagulable state induced by infection. Hypertens Res 2005;28: 619-23.

12. Covarrubias DJ, Luetmer PH, Campeau NG. Posterior reversible encephalopathy syndrome: prognostic utility of quantitative diffusion-weighted MR images. AJNR Am J Neuroradiol 2002;23:1038-48.

13. Doelken M, Lanz S, Rennert J, Alibek S, Richter G, Doerfler A. Differentiation of cytotoxic and vasogenic edema in a patient with reversible posterior leukoencephalopathy syndrome using diffusion-weighted MRI. Diagn Interv Radiol 2007;13:125-8.

14. Kapiteijn E, Brand A, Kroep J, Gelderblom H. Sunitinib induced hypertension, thrombotic microangiopathy and reversible posterior leukencephalopathy syndrome. Ann Oncol 2007;18:1745-7.

15. McCuskey RS, Urbaschek R, Urbaschek B. The microcirculation during endotoxemia. Cardiovasc Res 1996;32:752-63.

16. Tanioka R, Yamamoto Y, Sakai M, Makie T, Mori M, Uehira T, et al. Convalescence of atypical reversible posterior leukoencephalopathy syndrome in human immunodeficiency virus infection. J Med Invest 2007; 54:191-4

17. Bartynski WS, Boardman JF. Distinct imaging patterns and lesion distribution in posterior reversible encephalopathy syndrome. AJNR Am J Neuroradiol 2007;28:1320-7.

18. Varon J. Treatment of acute severe hypertension: current and newer agents. Drugs 2008;68:283-97. 